Takahito Inoue • Haruyoshi Yamaza • Yasuyoshi Sakai

Shin-ichi Mizuno • Mizuki Ohno • Naotaka Hamasaki

Yasuyuki Fukumaki

\title{
Position-independent human $\beta$-globin gene expression mediated by a recombinant adeno-associated virus vector carrying the chicken $\beta$-globin insulator
}

Received: November 20, 1998 / Received: December 26, 1998

\begin{abstract}
The position-independent expression of transgenes in target cells is an essential subject for determining effective gene therapies. The chicken $\beta$-globin insulator blocks the effects of regulatory sequences on transcriptional units at differential domains. We prepared a recombinant adeno-associated virus (rAAV) containing various combinations of the DNase I-hypersensitive site 2 (HS2), 3 (HS3), and 4 (HS4) core elements from the human $\beta$-globin locus control region (LCR), the human $\beta$-globin gene, and the herpes virus thymidine kinase promoter driven neomycinresistant gene $\left(\right.$ neo $\left.^{R}\right)$ (rHS432, rHS43, rHS42, rHS32, and rHS2), and also rAAV containing two copies of the 250-bp core sequence of the chicken $\beta$-globin insulator on both sides of the rHS2 (rIns/HS2/2Ins). After isolating neomycinresistant mouse erythroleukemia (MEL) cells infected with each rAAV, we analyzed the rAAV genome by Southern blots and polymerase chain reaction (PCR), using primers specific for HS core elements and the human $\beta$-globin gene. All clones contained a single copy of the rAAV genome in the chromosome, however, some of them had a rearranged proviral genome. In five clones with a single unrearranged rAAV genome for each rAAV construct, we assayed the expression of the human b-globin gene relative to the endogenous mouse $\beta^{\text {maj }}$-globin gene, using quantitative reverse transcriptase (RT)-PCR. In clones infected with rHS432, the expression level of the human $\beta$-globin gene ranged from $51.6 \%$ to $765.6 \%$ of that in the mouse $\beta^{\text {maj }}$ globin gene. Likewise, in rHS43, the expression level ranged from $36.7 \%$ to $259.0 \%$; in $\mathrm{rHS} 42$, from $47.8 \%$ to $207.0 \%$; in rHS32, from $47.9 \%$ to $105.4 \%$; and in rHS2, from $6.1 \%$ to $172.1 \%$, indicating a high variability of ex-
\end{abstract}

T. Inoue $\cdot$ H. Yamaza $\cdot$ Y. Sakai $\cdot$ S. Mizuno $\cdot$ M. Ohno $\cdot$ Y. Fukumaki $(\square)$ Division of Disease Genes, Institute of Genetic Information, Kyushu University, 3-1-1 Maidashi, Higashi-ku, Fukuoka 812-8582, Japan

Tel. +81-92-642-6167; Fax +81-92-632-2375

e-mail: yfukumak@gen.kyushu-u.ac.jp

N. Hamasaki

Department of Clinical Chemistry and Laboratory Medicine, Faculty of Medicine, Kyushu University, Fukuoka, Japan pression level in clones infected with recombinant virus lacking the insulator. In contrast, in clones infected with rIns/HS2/Ins, the range of expression of the human $\beta$-globin gene ranged from $52.8 \%$ to $58.3 \%$ of that in the mouse $\beta^{\text {maj }}$ globin gene. These results indicate that the insulator functioned dramatically to reduce the variability of transgene expression due to the position effect. This insulator-rAAV vector system holds promise to provide a constant level of transgene expression for gene therapy, regardless of the insertion sites on the chromosome.

Key words Gene therapy $\cdot \beta$-Globin gene $\cdot$ Adeno-associated virus $\cdot$ Position effect · Insulator

\section{Introduction}

Thalassemias are a group of inherited anemias characterized by the reduced production of globin chains (Weatherall and Clegg 1981). This syndrome occurs worldwide. Patients with severe phenotypes require erythrocyte transfusions that can be associated with life-threatening iron overload, despite intensive chelation (Wolfe et al. 1985). Bone marrow transplantation has been performed with some success, but this treatment is feasible in only a small percentage of affected patients (Lucarelli et al. 1990; Ferster et al. 1992). Pharmacologic approaches are intended to increase $\gamma$-globin gene transcription, leading to more effective erythropoiesis and/or decreased hemolysis in patients with $\beta$-thalassemia (Ley et al 1982). However, these treatments are potentially toxic, with unknown long-term complications. Gene addition strategies are rational approaches to the treatment of thalassemia syndromes. In early experiments, retrovirus-mediated gene transfer revealed that expression of the human $\beta$-globin gene was erythroid-specific, but insufficient for gene therapy application because expression of the human $\beta$-globin transgene was extremely low and integration site-dependent (Cone et al. 1987; Dzierzak et al. 1988). The prospects for increasing $\beta$-globin transgene expression to therapeutic levels were 
greatly improved by the discovery of the locus control region (LCR) of the human $\beta$-like globin gene cluster. The LCR confers erythroid-specific and elevated expression on a gene linked in cis. Some studies demonstrated that LCR sequences provided for chromosomal position-independent expression of linked genes, thus distinguishing them from classical enhancers (Grosveld et al. 1987; Ryan et al. 1989; Talbot et al. 1989; Blom van Assendelft et al. 1989). The LCR contains four DNase I-hypersensitive sites (HS) located 50-60 kb upstream of the human $\beta$-globin gene. It was subsequently shown that the activity of each HS was localized to core elements (Collis et al. 1990; Ney et al. 1990; Philipsen et al. 1990; Talbot et al. 1990; Pruzina et al. 1991). Expression studies in virally transduced cells showed that juxtaposed core elements of the LCR could enhance expression of the linked globin gene in an erythroid-specific fashion, but failed to reduce variability of expression due to integration sites (Walsh et al. 1992; Miller et al. 1993; Leboulch et al. 1994; Einerhand et al. 1995; Sadelain et al. 1995).

The Drosophila specialized chromatin structures (scs/scs') (Kellum and Schedl 1991; Kellum and Schedl 1992) and suppressor of the Hairy wing $(\mathrm{su}[\mathrm{Hw}])$-binding regions

(Holdridge and Dorsett 1991; Geyer and Corces 1992; Roseman et al. 1993) block enhancer-activated transcription in a positiondependent manner when placed between a gene and enhancer, without inactivating either the promoter or enhancer (Kellum and Schedl 1992; Holdridge and Dorsett 1991; Geyer and Corces 1992; Cai and Levine 1995; Scott and Geyer 1995). These insulators can confer position-independent expression on transgenes, when present in flanking positions, presumably by blocking effects from surrounding chromatin (Kellum and Schedl 1991; Roseman et al. 1993). An insulator role has also been demonstrated in the chicken globin LCR DNase I-hypersensitive site 4 (HS4) region (Chung et al. 1993) and the chicken lysozyme LCR A element (Bonifer et al. 1994). When the chicken HS4 region was tested in enhancer-blocking colony assays, the result was a reduction in the number of drug-resistant colonies when the selectable marker was flanked by these sites (Chung et al. 1993). The chicken HS4 region was also tested with the white gene in Drosophila and showed insulating properties (Chung et al. 1993) similar to those observed in the Drosophila, scs and scs' border elements. Most of the insulating activity of the chicken HS4 region resides in a 250-bp core region with multiple protein binding sites (Chung et al. 1997) and is located in a CpG island corresponding to the region of DNase I hypersensitivity (Chung et al. 1997).

One of final goals of genetic treatment for thalassemia syndromes is to introduce a functional globin transcription unit in hematopoietic stem cells and to express the transgene in a manner that is erythroid-specific, elevated, position-independent, and sustained over time. The present study was an attempt to elucidate the position effect of transduced gene expression. We selected a recombinant adeno-associated virus (rAAV)-mediated gene delivering system, for the following reasons: AAV is nonpathogenic (Berns and Bohenzky 1987), integration of the viral genome is efficient (Samulski et al. 1991; Kotin et al. 1992), virus integration appears to have no apparent effect on cell growth or morphology (Handa et al. 1977), there is a highly efficient transduction of human hematopoietic progenitor cells
(Goodman et al. 1994), and there is no possibility of a rearranged proviral genome due to unexpected splicing events commonly observed in the globin gene retroviral delivery system (Novak et al. 1990). We constructed a series of rAAV vectors containing the human $\beta$-globin gene and various combinations of HS core elements, and another rAAV vector containing two copies of the 250-bp core fragment of the chicken $\beta$-globin insulator in both sides of the HS-globin gene cassette. We observed consistent levels of expression of the human $\beta$-globin gene in the MEL clone derived by infecting only rAAV with the insulator, indicating that this optimized vector can reduce the variability of transgene expression after random insertion of viral vectors. The insulator could be highly pertinent for gene therapy using a $\mathrm{AAV}$ vector, in combination with potent transcriptional activators.

\section{Materials and methods}

\section{Cell culture}

Mouse erythroleukemia (MEL) cells were cultured in minimal essential medium (MEM) supplemented with $10 \%$ fetal bovine serum, $2 \mathrm{mM}$ glutamine, $100 \mathrm{IU} / \mathrm{ml}$ penicillin, and 100 $\mathrm{mg} / \mathrm{ml}$ streptomycin. HeLa cells were cultured in Dulbecco's modified Eagle's medium (DMEM) supplemented with 5\% fetal bovine serum, $4 \mathrm{mM}$ glutamine, $100 \mathrm{IU} / \mathrm{ml}$ penicillin, and $100 \mathrm{mg} / \mathrm{ml}$ streptomycin. All cultures were incubated at $37^{\circ} \mathrm{C}$ with $5 \% \mathrm{CO}_{2}, 95 \%$ air in a humidified incubator.

\section{Vectors and the helper plasmid}

We used psub201, an infectious AAV type2 recombinant plasmid and $\mathrm{pAAV} / \mathrm{Neo}$, in which the AAV coding region in psub201 was substituted for the herpes virus thymidine kinase promoter driven neomycin-resistant gene $\left(n e o^{R}\right)$. The helper plasmid pAd/AAV containing the AAV rep and cap genes flanked with adenoviral terminal repeat sequences were kindly obtained by Dr. T. Shenk of the Department of Biology, Princeton University.

\section{Construction of the recombinant adeno-associated virus} (rAAV) vector

The six rAAV plasmids we constructed are shown in Fig. 1. Each contains a Sna BI-Swa I fragment of the human $\beta$ globin gene and the neomycin resistance gene, under control of a herpes simplex virus thymidine kinase promoter. The elementary core HS fragments used were HS4 (a 280bp Sac I-Ana I), HS3 (a 224-bp Hph I-Fun 4HI), and HS2 (a 374-bp Hin dIII-Xba I) fragments obtained by PCR. To facilitate the subcloning of PCR fragments into the vector, nucleotide sequences of PCR primers for HS2 and HS4 were modified by adding the Pst I and $X b a$ I linkers within the $X b a$ I and $S a c$ I recognition sequences of sense primers, respectively. The following sets of primers were used for the preparation of each HS fragment: HS4A 5'-GATCTAGA 
Fig. 1A-F. Structure of the human $\beta$-globin cluster and the recombinant adeno-associated vivus (rAAV) plasmid. A Structure of the human $\beta$-globin gene cluster. The five functional genes $(\varepsilon, \mathrm{G} \gamma, \mathrm{A} \gamma, \delta$ and $\beta)$ are indicated by small black boxes. The position of the DNase I-hypersensitive site $(H S)$ regions in the locus control region (LCR) is indicated by arrows. HS fragments and the human $\beta$-globin gene used in the vector construction are indicated. B-F Structure of the rAAV plasmid containing various HS regions. Gray boxes indicate three coding regions of the human $\beta$-globin gene. Cloning sites used for the insertion of HS regions $(\mathrm{S}=$ Sac I, A=Ava I, Hp=Hph I, F=Fun 4HI, $\mathrm{X}=X b a \mathrm{I}, \mathrm{Hd}=H i n \mathrm{dIII}$ ) and Sna BI and Swa $\mathrm{I}$ in the $\beta$-globin gene are shown in $\mathbf{A}$. G The two copies of the 250-bp fragment of the core sequence of the chicken $\beta$-globin insulator (Ins) are inserted on both sides of rHS2 (F)
$\mathbf{A}$

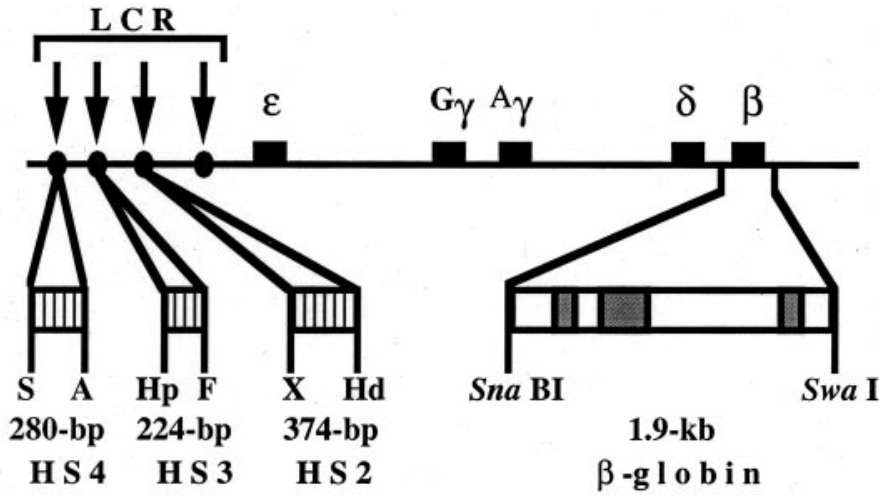

B rHS432

A AVHS4HS3HS2 $\quad \beta$-globin NeORAV

I T R

I T R

C rHS43

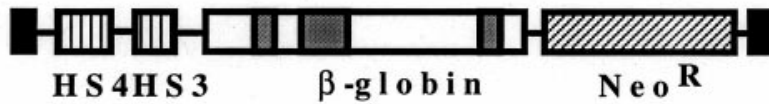

D rHS42

HIII

H S 4 H S 2

$\mathrm{Ne} \mathrm{o}^{\mathrm{R}}$
E $\quad$ rHS32

\section{F rHS2}

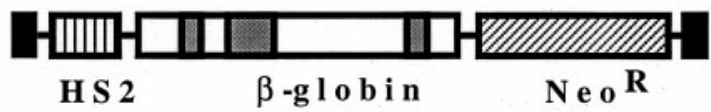

\section{G rIns/HS2/Ins}

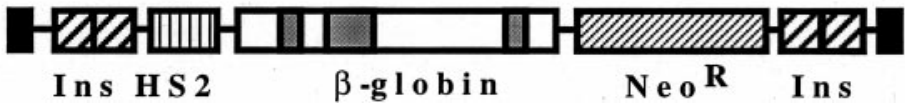

AGCTCTTGGGGACCCCAGTA- $3^{\prime}$, including the $X b a$ I site starting at the first nucleotide of the $S a c$ I recognition sequence, and HS4B 5'-TCACTAGTCTCGGGAATGGGAGGGAGAG-3', including the Spe I site ending at the Ava I site of the HS4 core fragment, HS3A 5'-GGAGATCTGGTGACTTTGCGAGCTGGTG- ${ }^{\prime}$, including the $\mathrm{Bgl}$ II site starting at the $\mathrm{Hph}$ I site and HS3B 5'TTGGATCCGCTGCTATGCTGTGCCTCCC-3', including the Bam HI site ending at the Fun 4HI site of the HS3 core fragment, and HS2A 5'-GAAATGCATAAGCTTCAGTTTTTCCTTAG- ${ }^{\prime}$, including the Nsi I site starting at the Hin dIII site and HS2B 5'-TCCTGCAGCTAGAATATGTCACATTCTG-3', including the Pst I site ending at the first nucleotide of the $X b a$ I recognition sequence of the HS2 core fragment. For PCR, $0.3 \mu \mathrm{g}$ of human genomic DNA was mixed with a final $0.2 \mu \mathrm{M}$ concentration of each primer and $0.2 \mathrm{mM}$ of each dNTP in reaction buffer containing $10 \mathrm{mM}$ Tris- $\mathrm{HCl}(\mathrm{pH} 9.0), 50$ $\mathrm{mM} \mathrm{KCl}, 2.5 \mathrm{mM} \mathrm{MgCl}_{2}$, and $0.1 \%$ Triton X-100. The mixture was heated at $94^{\circ} \mathrm{C}$ for $5 \mathrm{~min}$ for strand separation. One unit of Taq DNA polymerase (Promega, 2Madison, WI, USA) was then added and the following program was used: $94^{\circ} \mathrm{C} \times 1 \mathrm{~min}$, annealing for $1 \mathrm{~min}$ and $72^{\circ} \mathrm{C} \times 1 \mathrm{~min}$ for 30 cycles. The annealing temperatures of the sets of HS4A$\mathrm{HS} 4 \mathrm{~B}, \mathrm{HS} 3 \mathrm{~A}-\mathrm{HA} 3 \mathrm{~B}$, and HS2A-HS2B primers were $58^{\circ} \mathrm{C}$, $59^{\circ} \mathrm{C}$, and $55^{\circ} \mathrm{C}$, respectively. Amplified HS4, HS3, and HS2 
fragments were digested with $X b a$ I-Spe I, $B g l$ II-Bam HI, and $N s i$ I-Pst I, respectively, and were then subcloned into the multicloning-sites of pBluescript II SK+ (Stratagene, La Jolla, CA, USA). After the nucleotide sequences of these subclones had been determined by dideoxy methods, these subcloned fragments were digested with appropriate restriction enzymes and inserted between the two $X b a$ I sites present in psub201, to generate recombinant viral DNAs. The insulator core sequence was isolated from pJC5-4 as the Sal I-Hin dIII fragment. pJC5-4 was kindly provided by Dr. G. Felsenfeld, Laboratory of Molecular Biology, National Institutes of Health. This 250-bp fragment was ligated in tandem and inserted in both sides of rHS2. All fragments were subcloned in the same $5^{\prime}$ to $3^{\prime}$ orientation in psub201. Purification was accomplished by a $\mathrm{CsCl}$ density gradient formed in a vertical rotor at $52000 \mathrm{rpm}$.

The techniques used to produce $\mathrm{rAAV}$ were essentially the same as those described by Rolling and Samulski (1995), except that transfection of DNA was done by lipofection into 293 cells. In this study, transfection of DNA was done by calcium phosphate coprecipitation methods into HeLa cells.

\section{Titration of rAAV stocks}

To determine the biological titer of recombinant viral stock, dishes containing $80 \%$ confluent HeLa cells were infected with each rAAV stock up to $200 \mathrm{ml}$ for $24 \mathrm{~h}$. The infected HeLa cells were trypsinized, and replaced on three of $6 \mathrm{~cm}$ dishes. After $24 \mathrm{~h}, 800 \mathrm{mg} / \mathrm{ml}$ G418 (GIBCO-BRL, Gaithersburg, MD, USA) was added to the culture medium, and numbers of G418-resistant colonies were counted 10-14 days after transduction. The order of viral titer was approximately 1 to $5 \times 10^{4} \mathrm{cfu} / \mathrm{ml}$.

rAAV-mediated transduction of MEL and clonal selection

Approximately $5 \times 10^{5}$ MEL cells were infected separately with each rAAV stock, at a multiplicity of infection (MOI) of 0.1 , and incubated at $37^{\circ} \mathrm{C}$ for $48 \mathrm{~h}$. Infected MEL cells were washed with phosphate-buffered saline (PBS), and, resuspended in G418 medium at a final concentration of $800 \mu \mathrm{g} /$ $\mathrm{ml}$. For further purification, G418-resistant cells were plated in semisolid medium containing $1.5 \%$ methylcellulose and $800 \mu \mathrm{g} / \mathrm{ml} \mathrm{G} 418$. After 7-10 days, several G418-resistant colonies of MEL cells were taken from the cultures, using a Pasteur pipette, and placed in suspension culture.

Analysis of the rAAV genome structure in infected cells

Genomic DNA was extracted from each clone, as described (Sambrook et al. 1989). Organization of the human $\beta$-globin gene and HS fragments was examined by PCR, using the specific primers described below. The $5^{\prime}$ part of the human b-globin gene was amplified using human $\beta$-globin genespecific primers EE1 (5'-CTTACATTTGCTTCTGACAC- $\left.3^{\prime}\right)$ and EE2 (5'-ACAGATCCCCAAAGGACTCAAAG-3'), located within the region containing the cap site and the second exon of the human $\beta$-globin gene, respectively, generating a 334-bp PCR-amplified fragment. Individual HS fragments were amplified using HS-specific primers (HS4A-HS4B), (HS3A-HS3B), and (HS2A-HS2B), which generate 280-bp, 220-bp, and 370-bp fragments, respectively. To determine the genome arrangement and copy number, $10 \mu \mathrm{g}$ of genomic DNA from rHS432, rHS43, rHS42, and rHS32 clones and rHS2 and rIns/HS2/Ins clones was digested with Pst I, Kpn I, or Hin dIII and Hin dIII, $K p n$ I or Kpn I and Hin cII, respectively. Each DNA sample was fractionated by $0.6 \%$ agarose gel electrophoresis in Tris-borate ethylediamine tetracetate (TBE) buffer, transferred to HybondN+ (Amersham, Arlington Heights, IL,USA), and then hybridized with an Eco RI-Bam HI ${ }^{32} \mathrm{P}-$ labeled fragment of the human $\beta$-globin gene. The filters were washed once with $2 \times$ standard saline citrate (SSC)/ $0.1 \%$ sodium dodecyl sulfate $(\mathrm{SDS})$, once with $0.5 \times \mathrm{SSC} /$ $0.1 \%$ SDS, and twice with $0.2 \times \mathrm{SSC} / 0.1 \%$ SDS, each at $65^{\circ} \mathrm{C}$ for $15 \mathrm{~min}$. The hybridized probe was detected on autoradiography. The copy number of the transduced gene in rHS432, rHS43, rHS42, and rHS32 was obtained by densitometry of the $\beta$-globin DNA signal of the Pst I, Kpn I, or Hin dIII band of genomic DNA on Southern blots and compared with that obtained for each AAV plasmid DNA and for two copies of the human $\beta$-globin gene in the HeLa genome. Likewise, the copy number of the transduced gene in rHS2 and rIns/HS2/Ins was determined by densitometry of the b-globin gene signal of the Hin dIII, Kpn I, or Kpn IHin cII band derived from the genomic DNA of each clone to the corresponding band of each $\mathrm{rAAV}$ plasmid DNA and the HeLa genome.

\section{Expression analysis}

Expression of the globin gene was analyzed using quantitative reverse transcriptase-PCR (RT-PCR). Total RNA was extracted from each clone, using Isogen (Nippon Gene, Tokyo, Japan). The RT reaction was performed using an RNA PCR kit (Perkin Elmer, Branchburg, NJ, USA). For $\mathrm{RT}, 2.5 \mu \mathrm{g}$ of total RNA was heated at $65^{\circ} \mathrm{C}$ for 2 min and then placed on ice. Total RNA was mixed with $2.5 \mu \mathrm{M}$ random hexamers, $1 \mathrm{mM}$ each dNTP, $10 \mathrm{mM}$ Tris- $\mathrm{HCl}(\mathrm{pH}$ 8.3), $50 \mathrm{mM} \mathrm{KCl}, 5 \mathrm{mM} \mathrm{MgCl}_{2}, 1 \mathrm{U} / \mu \mathrm{l}$ RNase Inhibitor, and $2.5 \mathrm{U} / \mu \mathrm{l} \mathrm{MuLV}$ reverse transcriptase in a total volume of 25 $\mu$, including an RNA specimen. The RT reaction was as follows: One cycle of $42^{\circ} \mathrm{C}$ for $15 \mathrm{~min}, 99^{\circ} \mathrm{C}$ for $5 \mathrm{~min}$, and $5^{\circ} \mathrm{C}$ for 5 min. PCRs were performed using HE1 (5'GAGGAGAAGTCTGCCGTTACTGC- ${ }^{\prime}$ ) and HE2 (5'CATTAGCCACACCAGCCACCACT-3') located within the first and second exons of the human $\beta$-globin gene, respectively, generating a 403-bp PCR-amplified fragment. ME1 (5'-GCTGAGAAGGCTGCTGTCTCTTG-3') and ME2 (5'-GGCCCAGCACAATCACGATCATA-3'), specific for the first and second exons of the mouse $\beta^{\text {maj }}$-globin gene, respectively, were used to generate a 331-bp PCRamplified fragment. Five $\mu l$ of the synthesized cDNA was used as the template for PCR, under the following conditions: for the human $\beta$-globin gene, 25 cycles of $94^{\circ} \mathrm{C}$ for 1 
$\min , 65^{\circ} \mathrm{C}$ for $1 \mathrm{~min}$, and $72^{\circ} \mathrm{C}$ for $1 \mathrm{~min}$; for the mouse $\beta^{\text {maj }}$ globin gene, 25 cycles of $94^{\circ} \mathrm{C}$ for $1 \mathrm{~min}, 70^{\circ} \mathrm{C}$ for $1 \mathrm{~min}$, and $72^{\circ} \mathrm{C}$ for $1 \mathrm{~min}$. PCR products were separated on $2 \%$ agarose gels and stained with Vistra Green (Amersham, Arlington Heights, IL, USA) to a final dilution of 1: 10000 in Tris-EDTA (TE). The fluorochrome intensity of specific fragments was detected using a Fluoro Imager system (Molecular Dynamics, Sunnyvale, CA, USA) and analyzed using Image QuaNT software (Molecular Dynamics). Expression of the transduced gene was assessed as a percentage of the mRNA-derived intensity from the human $\beta$ globin gene in relation to that from the mouse $\beta^{\text {maj }}$-globin gene. The percentages were calculated as follows:

$\frac{\text { human } \beta \text {-RNA }}{\text { mouse } \beta^{\text {maj }} \text {-RNA }} \times \frac{\text { mouse } \beta^{\text {maj }} \text { gene copy no. }}{\text { human } \beta \text { gene copy no. }}$
$\times \frac{\text { fragment length of mouse RT-PCR }}{\text { fragment length of mouse RT-PCR }}$

This value was determined for each of three RT-PCR trials, and the mean and SD of the mean were calculated.

\section{Fluorescence in-situ hybridization (FISH)}

The techniques used for FISH were essentially the same as those described by Lichter et al. (1988). Briefly, rIns/HS2/Ins clones were cultured in MEM with $1.5 \mu \mathrm{g} / \mathrm{ml}$, 3-(1anilinoethylidene)-5-benzylpyrrolidine-2, 4-dione (TN-16) (Wako Pure Chemical Industries, Osaka, Japan) for $2 \mathrm{~h}$ to enrich metaphase cells. The cells were treated with hypotonic solution $(0.075 \mathrm{M} \mathrm{KCl})$ and fixed with cold methanol-glacial acetic acid (3:1). Metaphase cells were washed with fixative, dropped on cold slides and air dried. rIns/HS2/Ins plasmids $(1.5 \mu \mathrm{g})$ were labeled with biotin-16-deoxyuridine triphasphate (dUTP) with a nick translation kit (Boehringer Mannheim, Mannheim, Germany). About $100 \mathrm{ng}$ of labeled probes was mixed with $1.5 \mu \mathrm{g}$ of mouse Cot-I DNA and $5 \mu \mathrm{g}$ of salmon sperm DNA. After denaturation of the probe mixture $\left(75^{\circ} \mathrm{C}\right.$ for $10 \mathrm{~min})$, the probes were preannealed $\left(37^{\circ} \mathrm{C}\right.$ for $\left.10 \mathrm{~min}\right)$ to block non-specific signals and hybridized to denatured metaphase chromosome specimens prepared from rIns/HS2/ Ins clones. After incubation for $48 \mathrm{~h}$ and subsequent posthybridization washes, the specimens were treated with blocking solution ( $3 \%$ bovine serum albumin, $4 \times$ SSC, and $0.1 \%$ Tween 20). Biotin labeled probes were amplified using avidin and biotin-conjugated anti-avidin antibodies, and then detected by fluorescein isothiocyanate (FITC)-conjugated avidin (Boehringer Mannheim, Mannheim, Germany) followed by 4,6diamidino-2-phenylindole (DAPI) counterstaining. Individual signals were collected using a fluorescence microscope coupled to a charged coupled devise (CCD) camera (Axiophot; Zeiss, Jena, Germany) and merged using Probe Vision software (Applied Imaging, Santa Clara, CA, USA).

\section{Results}

rAAV-mediated transduction of the human $\beta$-globin gene with various combinations of HS fragments

To evaluate the effects of HS regions on $\beta$-globin gene expression in the AAV-mediated gene delivery system, we prepared rAAV constructs that contained various combinations of HS core elements linked to the human $\beta$-globin gene. MEL cells were infected separately with each rAAV construct, rHS432, rHS43, rHS42, and rHS32, at an MOI of 0.1. Ten single neomycin-resistant clones were isolated from each rAAV construct. For each clone, the presence of an intact HS region and the b-globin gene region was evaluated by PCR (See Materials and methods). The 334-bp specific PCR fragment of the $5^{\prime}$ part of the human $\beta$-globin gene was present in all clones. However, the specific PCR fragments of the HS regions were not evident in two, three, one, and four of ten rHS432, rHS43, rHS42, and rHS32 clones, respectively, suggesting that the rAAV genome was rearranged in the host chromosome of these clones (data not shown). To examine integration and the copy number of the rAAV genome, Southern blot analysis was performed, using Pst I digested genomic DNA derived from each clone. Restriction digestion with Pst I resulted in an unrearranged internal genomic band of a predicted length, 2.2$\mathrm{kb}$ for rHS432, rHS42, and rHS32 and 2.5-kb for rHS43, because Pst I cut twice in each construct. All ten clones of rHS432 contained the intact human $\beta$-globin gene, while three, two, and one of ten clones contained a rearranged genome, as reflected by a Pst I band that deviated in length from that predicted in rHS43, rHS42, and rHS32, respectively. Digestion with $K p n \mathrm{I}$, which cuts once in each rAAV genome, generates a junction fragment, the length of which depends on the integration site. Southern blots of genomic DNA from all clones with the unrearranged rAAV genome of each construct showed that the single Kpn I fragments in each clone were of unique size. Representative results of Southern blot analysis of DNA from five rHS432 clones are shown in Fig. 2. To exclude head-to-head tandem integration, we performed Southern blots of genomic DNA digested with Hin dIII, which cuts at the $5^{\prime}$ to the b-globin gene. One hybridizing band per transduced clone was also observed using the same probe on a Southern blot of genomic DNA from all clones (data not shown). These observations indicate that a single copy of the rAAV genome integrated at different sites on the chromosome. A single copy of the transduced rAAV genome was also confirmed by densitometric measurement of the signal from each band on Southern blots, compared with that from each rAAV plasmid DNA and the HeLa genome.

Expression of the transduced human $\beta$-globin gene

Total RNA was extracted from five clones for each rAAV construct which proved to contain a single and unrearranged vector genome at different sites on the host chromosome. Products of the human $\beta$-globin gene, amplified using ME1ME2 primers, and the mouse $\beta^{\text {maj }}$-globin gene, amplified 
Fig. 2A-C. Southern blot analysis of $\mathbf{A}$ Pst I and $\mathbf{B}$ Kpn I -digested DNA from rHS432 clones. DNAs submitted to Southern blot analysis were extracted from five independent neomycin-resistant clones of rHS432 (lanes 1, 2, 3, 4, and 5). Lane HeLa contains Pst I- or $K p n$ I-digested DNA from $\mathrm{HeLa}$ cells, as a positive control, and lane MEL contains $P$ st I- or Kpn I-digested DNA from mouse erythroleukemia (MEL) cells, as a negative control. The human $\beta$-globin probe was prepared by radiolabelling a 917 bp fragment flanked by Bam $\mathrm{HI}$ and Eco RI restriction sites. Tick marks indicate the position of the Lambda Sty I marker. C Schematic of the integrated rHS432 genome. Pst I digestion of the integrated rAAV genome results in a 2.2$\mathrm{kb}$ insert containing the human $\beta$-globin gene. Kpn I digestion generates a junction fragment hybridized with the human $\beta$ globin probe
A Pst I

B Kpn I

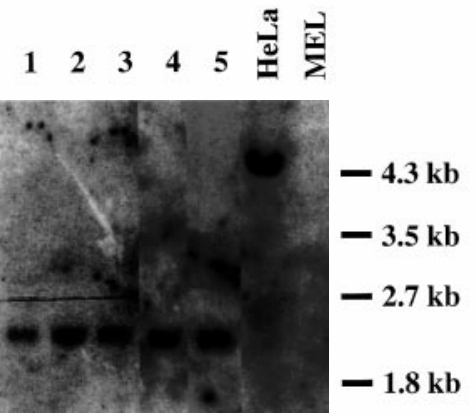

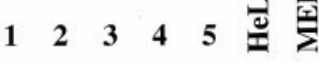

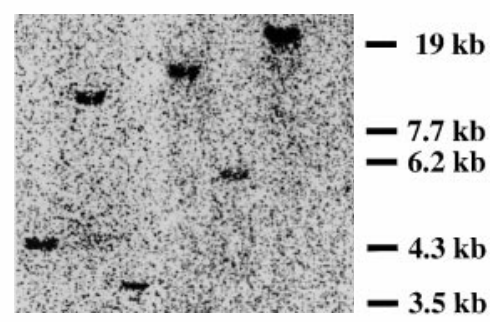

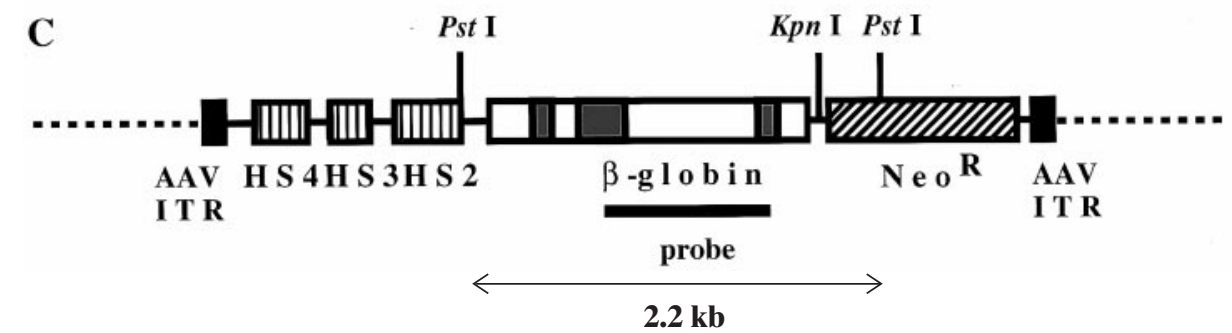

using E1-E2 primers, were not detected in all analyses, indicating the specificity of each primer set in the RT-PCR method. Negative control reaction mixtures contained RT reaction mixtures that were prepared without the addition of RNA. Products of the human $\beta$-globin and mouse $\beta^{\text {maj }}$ globin gene amplified using these samples were not detected in all analyses. To determine the optimal condition for detection and quantitation of human $\beta$-globin gene expression, the relative yields of PCR products for the human reticulocytes and MEL cells were determined after various numbers of PCR cycles. We found that the kinetics of amplification of the human $\beta$-globin-specific PCR products were similar to those of the mouse $\beta^{\text {maj }}$-globin-specific products in the human reticulocytes and MEL cells (data not shown). At 25 cycles of PCR, the relative yields of both PCR products were within the linear range of amplification before saturation at the plateau, indicating that it is possible to compare the initial amounts of mRNA template in the human $\beta$-globin and mouse $\beta^{\text {maj }}$-globin cDNA samples (data not shown). An estimate of expression was made as the ratio of human $\beta$-globin/mouse $\beta^{\text {maj }}$-globin gene signal intensity (See Materials and methods). RT-PCR signals are shown in Fig. 3A, C, E, G and are graphically presented in Fig. $3 \mathrm{~B}, \mathrm{D}, \mathrm{F}, \mathrm{H}$. The expression per copy of the rAAV genome ranged from $51.6 \%$ to $765.6 \%$ of a single copy of the mouse $\beta^{\text {maj }}$-globin gene with a mean expression level of $240.4 \%$ in the rHS432 clones. Likewise, the expression level ranged from $36.7 \%$ to $259.0 \%$ with a mean of $140.7 \%$ in the rHS 43 clones, $47.8 \%$ to $207.0 \%$ with a mean of $130.7 \%$ in the rHS42 clones; and $47.9 \%$ to $105.4 \%$ with a mean of $77.6 \%$ in the rHS32 clones. Variability in the level of expression was observed in individual clones derived from each $\mathrm{AAV}$ construct, indicat- ing that HS core elements are not capable of conferring position-independent expression to the linked gene.

Effect of the insulator on expression of the $\beta$-globin gene

To overcome the position effect variegation we prepared rAAV which contained two copies of the 250-bp insulator core sequence of the chicken $\beta$-globin gene in both sides of the HS2, the $\beta$-globin gene and the neo gene cassette. Five single neomycin-resistant colonies were isolated from MEL cells infected with rIns/HS2/Ins. Nine clones from rHS2infected MEL cells, which have no insulator, were also isolated as a control. We examined the integration and structure of the rAAV genome in the host chromosome by Southern blotting and PCR, using primers specific for the $\beta$-globin gene and the HS2 region. PCR analysis showed the presence of the transduced human $\beta$-globin gene in all clones of rIns/HS2/Ins and rHS2. The HS2 region was detected in seven of nine clones of rHS2 and all of rIns/HS2/ Ins. Restriction digestion with Hin dIII located within the $\mathrm{rIns} / \mathrm{HS} 2 / \mathrm{Ins}$ genome released the predicted $3.3-\mathrm{kb}$ unrearranged genomic fragment in all $\mathrm{rIns} / \mathrm{HS} 2 / \mathrm{Ins}$ clones (Fig. 4A). We also did a Southern blot analysis of genomic DNA digested by both Kpn I and Hin cII, which cut once and uncut the rIns/HS2/Ins genome, respectively. The results show the presence of fragments of various sizes, indicating that a single copy of the rIns/HS2/Ins genome integrated at different sites on the host chromosome (Fig. 4B). For further evaluation of the integration site of the rIns/HS2/Ins genome, FISH was performed (as described in Materials and methods). A signal of the human $\beta$-globin 
Fig. 3A-H. Expression of the human $\beta$ globin gene transduced by rAAV with various combinations of HS regions in MEL clones. Reverse transcriptasepolymerase chain reaction (RT-PCR) products of RNA extracted from five individual clones with a single unrearranged rAAV vector genome for each construct are shown, $\mathbf{A}, \mathbf{B}$ rHS 432 clones, $\mathbf{C}, \mathbf{D}$ rHS43 clones, $\mathbf{E}, \mathbf{F}$ rHS42 clones, and $\mathbf{G}, \mathbf{H}$ rHS32 clones. The relative amount of human $\beta$-globin mRNA is expressed as a percentage ratio of human $\beta$-globin RT-PCR products to mouse $\beta^{\text {maj }}$-globin RT-PCR products. The data represent average values obtained from three independent RT-PCR experiment

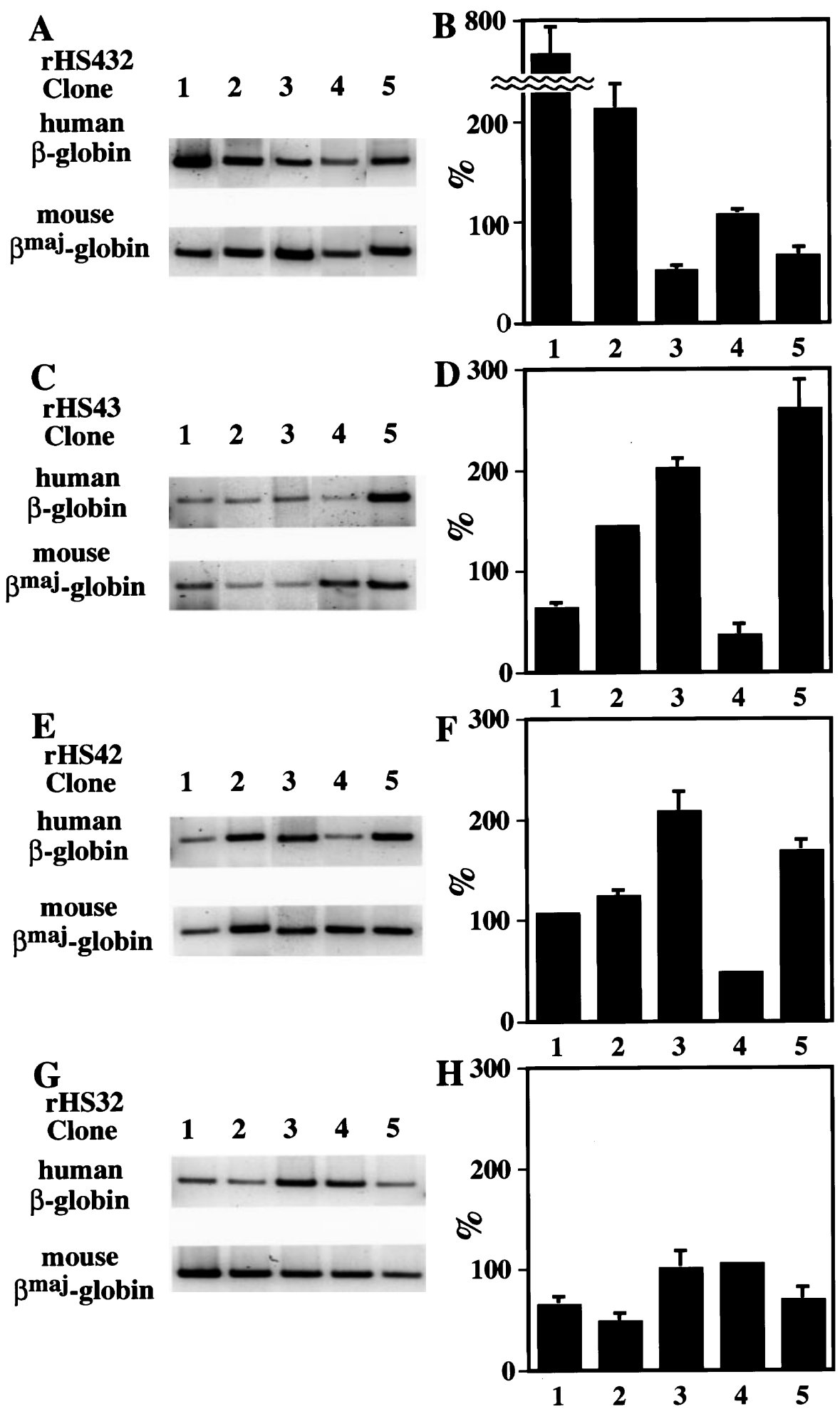

gene was detected at a single integration site in all rIns/HS2/ Ins clones and each signal was present on a different chromosome. Representative results of FISH analysis of two clones are shown in Fig. 5. These results are in good agreement with the observations of Southern blot analysis. Southern blots of genomic DNA digested with either Pst I or both Kpn I and Hin dIII from nine rHS2 clones showed that seven of the nine had a single and unrearranged rAAV genome at different sites on the chromosome (data not shown). To measure the expression of the human $\beta$-globin gene, total RNA was isolated from five clones with a single unrearranged rAAV genome in the chromosome for each construct. RT-PCR analysis was done using specific primers for the human $\beta$-globin and mouse $\beta^{\text {maj }}$-globin genes (See Material and methods) of these five clones. RT-PCR signals are shown and graphically presented in Fig. 6. In rHS2 
Fig. 4A-C. Southern blot analysis of $\mathbf{A}$ Hin dIII and $\mathbf{B}$ Kpn I and Hin cII -digested DNAs from rIns/HS2/Ins clones. DNAs extracted from five independent neomycin-resistant clones of rIns/HS2/Ins were submitted to Southern blot analysis. Lane HeLa contains Hin dIII- or Kpn I and Hin cII-digested DNA from HeLa cells, as a positive control and lane MEL contains Hin dIII- or Kpn I and Hin cII-digested DNA from MEL cells, as a negative control. The human $\beta$ globin probe was prepared by radiolabelling a 917-bp fragment flanked by Bam HI and Eco RI restriction sites. Tick marks indicate position of the Lambda Sty I marker. C Schematic of the integrated rIns/ HS2/Ins genome. Hin dIII digestion generates a $3.3-\mathrm{kb}$ insert containing the human $\beta$ globin gene. Double digestion with Kpn I and Hin cII results in a junction fragment hybridized with the human $\beta$-globin probe
A Hin dIII

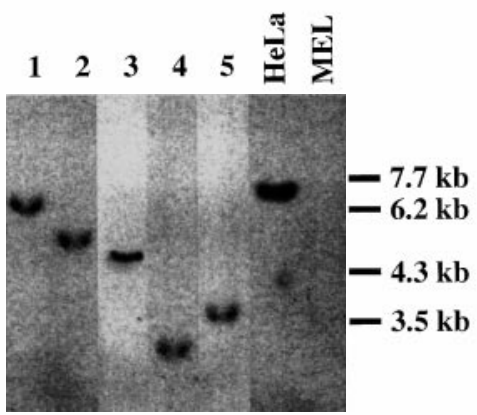

B Kpn $\mathrm{I} / \mathrm{Hin}$ cII

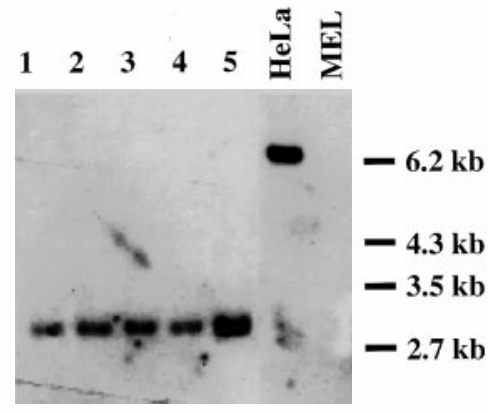

C Hin cII

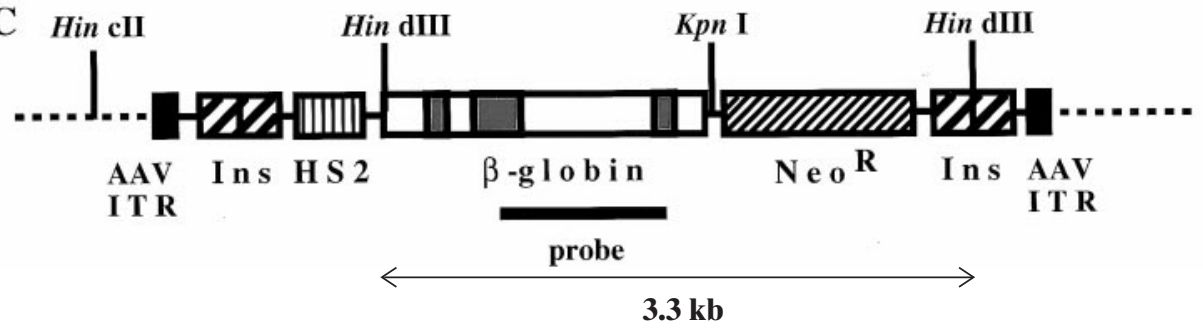

A

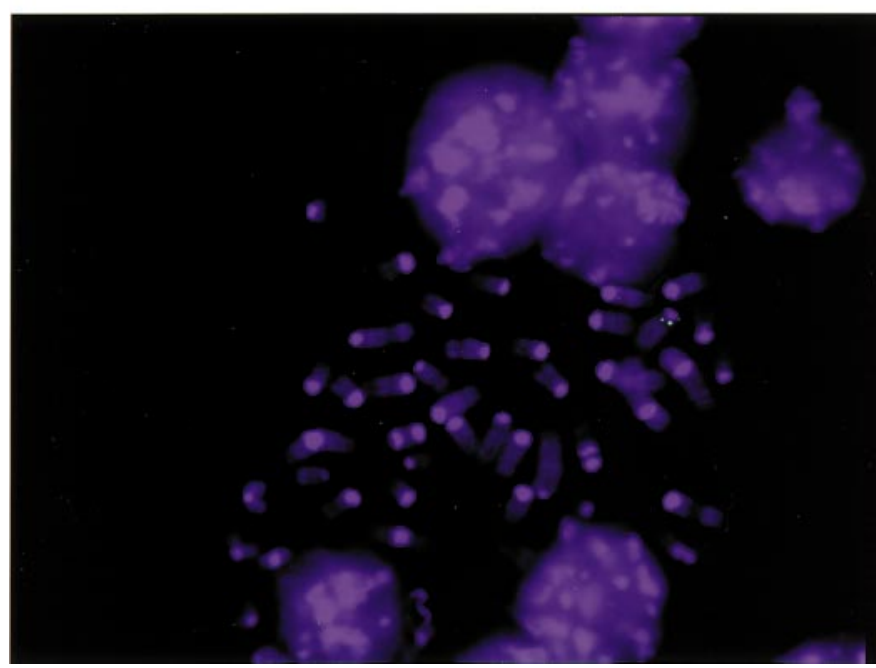

Fig. 5A, B. Fluorescence in-situ hybridization analysis of metaphase chromosome from rIns/HS2/Ins clones. Metaphase chromosomes of two independent rIns/HS2/Ins clones A and $\mathbf{B}$ were hybridized with the biotin-labeled rIns/HS2/Ins probe with subsequent signal detection by
B

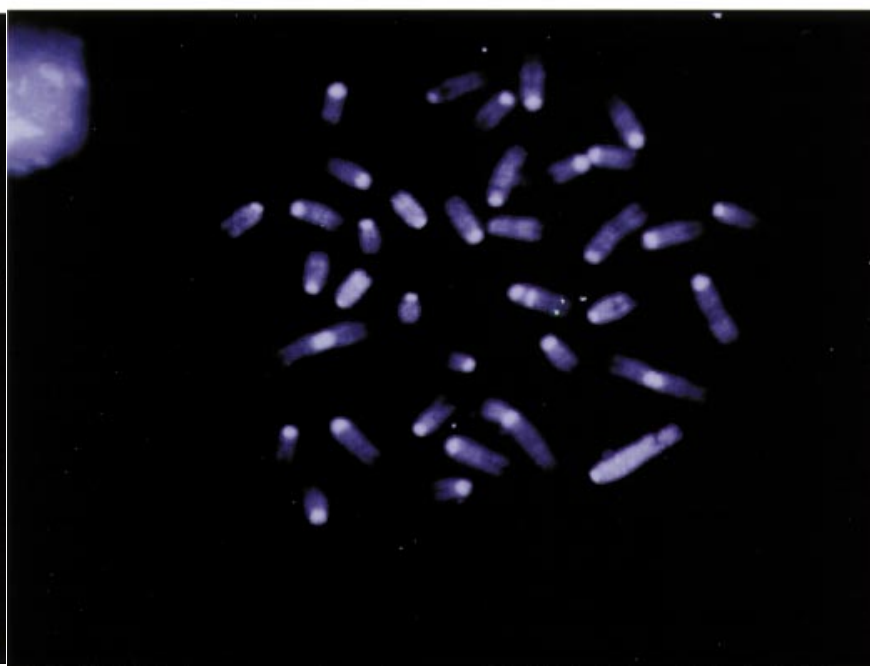

fluorescein isothiocyanate (FITC). A single integration of the rIns/ HS2/Ins genome was shown at each clone. Each signal of the clones in $\mathbf{A}$ and $\mathbf{B}$ was present on a different chromosome. Chromosomes were counterstained with 4-6-diamidino-2-phenylindole (DAPI) clones, the levels of human $\beta$-globin expression ranged from $6.1 \%$ to $172.1 \%$, with the mean expression being $51.0 \%$ of the endogenous mouse $\beta^{\text {maj }}$-globin mRNA level. In contrast, rIns/HS2/Ins clones revealed nearly consistent levels of human b-globin mRNA, compared with the mouse bmajglobin expression $(52.8 \%-58.3 \%$, with a mean expression level of $56.2 \%$ ).

\section{Discussion}

We evaluated the effects of the HS elements of the LCR of the b-globin gene cluster and a chicken $\beta$-globin insulator on variability of expression of the $\beta$-globin gene transduced by rAAV. The mean expression level of rHS432, rHS43, 
Fig. 6. Expression of the human bglobin gene transduced by rAAV, with and without the insulator in MEL clones. RT-PCR products of RNA extracted from five individual clones with a single unrearranged rAAV vector genome for each construct are shown A, B rHS2 clones; C, D rIns/HS2/ Ins clones. The relative amount of human b-globin mRNA is expressed as a percentage ratio of human b-globin RT-PCR products to mouse bmaj-globin RT-PCR products. The assay was done in triplicate on individual clones
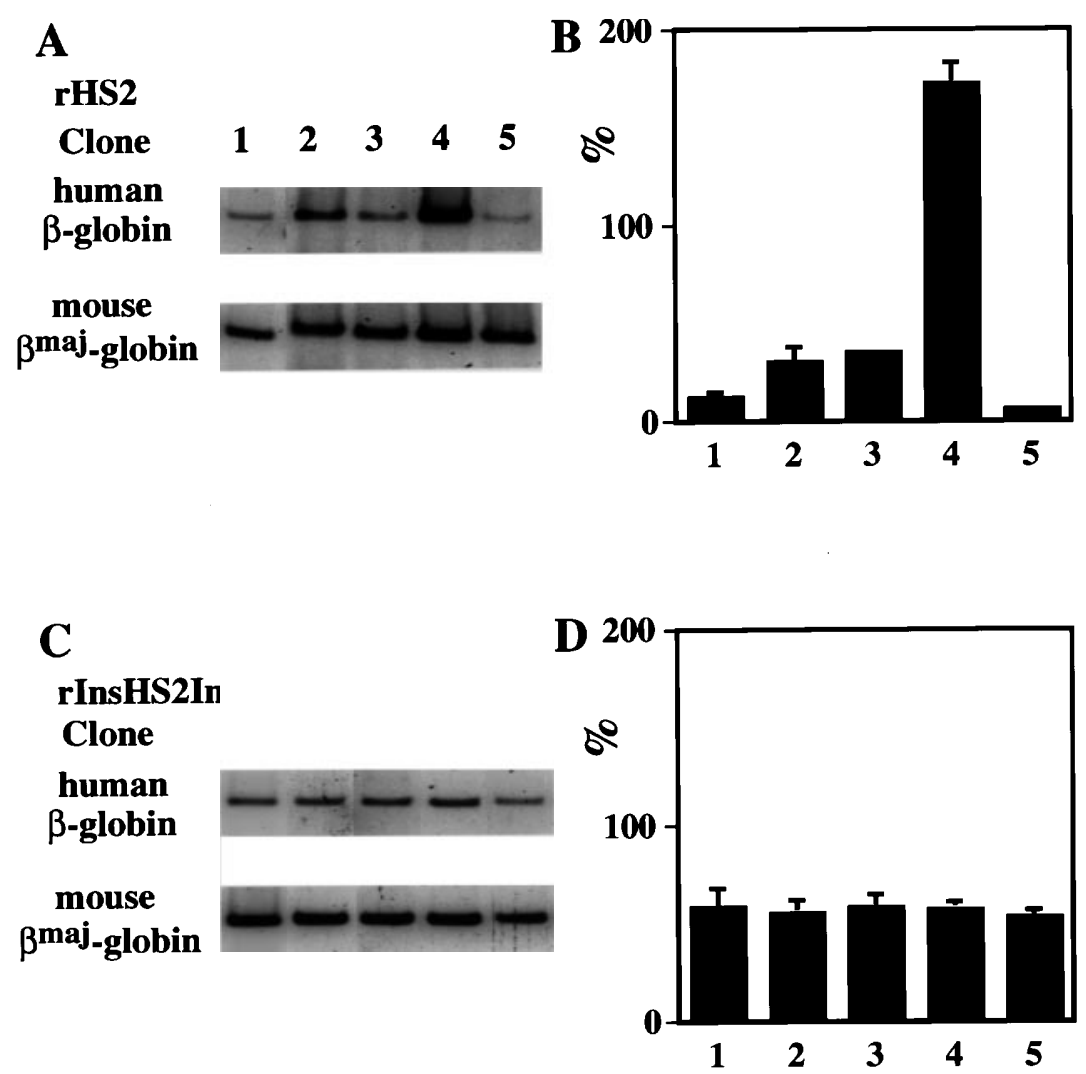

rHS42, rHS32, and rHS2 clones was 240.4\%, $140.7 \%$, $130.7 \%, 77.6 \%$, and $51.0 \%$, respectively, of the level of the mouse $\beta^{\text {maj }}$-globin expression. The highest mean value was observed in rHS432 clones, indicating that the rAAV vector containing all of HS4, HS3, and HS2 elements rather than HS43, HS42, HS32, or only HS2 elements had a greater effect on increasing expression of the human $\beta$-globin gene. However, the human $\beta$-globin expression levels varied, irrespective of the combination of HS elements. Expression levels of the transduced human $\beta$-globin gene in rHS432, rHS43, rHS42, rHS32, and rHS2 clones varied by more than 14-fold, the range being $51.6 \%-765.6 \%$ relative to endogenous mouse $\beta^{\text {maj }}$-globin expression, and sevenfold, fourfold, twofold, and 28-fold, respectively. Other investigators have also used AAV vectors with core elements of the human $\beta$-globin LCR linked to either the human $\beta$ - or $\gamma$ globin gene (Walsh et al. 1992; Miller et al. 1993; Leboulch et al. 1994; Einerhand et al. 1995; Sadelain et al. 1995). However, the effects of only HS2 and HS432 on globin gene expression were evaluated. Although erythroid-specific expression increased, the expression levels of the transduced human globin gene varied. These results indicate that transcription of the gene with the HS region was not independent of the integration site and was affected by flanking chromatin regions. In transgenic mice, however, the LCRlinked b-globin transgene was expressed in a position-independent and a copy number-dependent manner (Grosveld et al. 1987; Ryan et al. 1989; Talbot et al. 1989; Blom van Assendelft et al. 1989). The discrepancy in position-independent expression due to LCR is difficult to explain. It may be that a regulatory sequence like an insulator, a cis- acting element that shields the transcriptional units from the surrounding DNA, exists in the full-length LCR but not in HS core elements. In fact, LCR containing HS4, 3, 2, 1 does not confer position-independent expression onto the b-globin promoter-driven lac $\mathrm{Z}$ gene in transgenic mice (Guy et al. 1996; Guy et al. 1997). HS5 59 to HS4 was shown to have the properties of an insulator ( $\mathrm{Li}$ and Stamatoyannopoulos 1994). At present, the site of integration usually cannot be chosen or controlled because viral vectors integrate at random into the chromosomes of target cells. An insulator is recommended to elude position-effect after integration by viral vectors. A number of insulators have been detected in Drosophila (Kellum and Schedl 1991; Kellum and Schedl 1992; Holdridge and Dorsett 1991; Geyer and Corces 1992; Roseman et al. 1993; Cai and Levine 1995; Scott and Geyer 1995), chickens (Chung et al. 1993; Bonifer et al. 1994), and humans ( $\mathrm{Li}$ and Stamatoyannopoulos 1994; Kalos and Fournier 1995). A study of the chicken b-globin locus suggested that the chromatin near the 59 constitutive DNase I-hypersensitive site was condensed (Reitman and Felsenfeld 1990). It has subsequently become apparent that a sequence at the 59 end of the chicken b-globin locus, containing a constitutive DNase I-hypersensitive site, can function as an insulator (Chung et al. 1993). Most of the insulating activity lies in a 250-bp core element, which contains the constitutive DNase I-hypersensitive site (Chung et al. 1997).

We expected that an rAAV vector with an insulator would be capable of reducing the variability of expression of transduced genes. One limitation of the AAV system for gene therapy is that the virion can package DNA only up to 
$5.0 \mathrm{~kb}$ (Berns and Bohenzky 1987). In this study, a 250-bp fragment was ligated in tandem and inserted in both sides of rHS2 because of size limitation for efficient packaging of the viral genome. We demonstrated that the minimal insulator comprising juxtaposed tandem copies of the 250-bp core sequence provided insulator function in MEL cells infected by the rAAV vector. These findings indicate that this minimal insulator would exert effects on chromatin structure and overcome position effect variegation in gene therapy. How are insulator sequences capable of preventing position effects on the transcription unit and do they block the effects of regulatory sequences on neighboring sequences at the site of integration? They may act either by preventing tracking of a distant enhancer complex along chromatin or by blocking access to any factors outside the loop formed by the interaction of the $5^{\prime}$ insulator with the $3^{\prime}$ insulator (Chung et al. 1993; Corces 1995). Further, it is also noteworthy that a 250-bp element used in this study has the properties of a CpG island (Chung et al. 1997). Mechanisms of the insulator function remain unknown.

Most current gene therapy approaches make use of viral vectors (Verma and Somia 1997). This is a powerful technique, as specific machinery has evolved to deliver genes to cells. In recent years, the AAV vector has received increased attention because of its potential as a vector for gene therapy, and recent studies have shown that the AAV vector could be used to introduce specific genetic changes into the genomic DNA of mammalian cells, including a therapeutic gene targeting application (Russell and Hirata 1998). AAV is non-pathogenic (Berns and Bohenzky 1987), resistant to chemical and physical treatments (Berns and Bohenzky 1987), and infects various types of tissues, such as brain (McCown et al. 1996), liver (Snyder et al. 1997a), retina (Ali et al. 1996; Ali et al. 1998), and skeletal muscle (Fisher et al. 1997; Snyder et al. 1997b). However, a study using immortalized epithelial cells indicated that the rAAV vector integrated at a low frequency and persisted as an episome in infected cells (Kearns et al. 1996). Recently, less efficient integration of the rAAV in the human erythropoietic cell line, K562, was reported (Malik et al. 1997), indicating that AAV is not necessarily an appropriate system for gene transfer to human hematopoietic progenitor cells. We observed that a single rAAV vector genome integrated at random in host chromosomes on target cells, as determined by Southern blot analysis of genomic DNA and FISH analysis in this rAAV-MEL cell system. Long-term expression of the human globin gene was observed in bone marrow of recipient mice reconstituted by low-density bone marrow mononuclear cells infected with an rAAV carrying the human globin gene (Ponnazhagan et al. 1997), suggesting the potential usefulness of the AAV-based vector system in gene therapy for human hemoglobinopathies. For gene therapy, expression levels of the transduced gene must persist long-term. We are currently investigating the effects of the insulator on the stability of the vector genome and expression levels of the transduced gene in continuous longterm culture.

As this insulator protects the white minigene from position effects in transgenic Drosophila and as AAV has a wide range regarding susceptible cell type, rAAV with the insulator could be an effective gene delivery system to provide consistent expression of non-erythroid genes in target tissues, in addition to the globin gene reported here. This system not only decreases the variability of expression of a transduced gene but also avoids activation of an oncogene near the insertion site of the recombinant viral genome.

Acknowledgments We are grateful to Dr. T. Shenk of Princeton University and Dr. G. Felsenfeld of the National Institutes of Health for generously providing the AAV vectors and the chicken $\beta$-globin insulator, respectively. We thank Dr. K. Miyamura, Nagoya University, for valuable suggestions in the preparation of rAAV stock, and Ms. C. Wakamatsu for assistance in the initial part of this work. Language assistance was provided by Ms. M. Ohara. This work was supported in part by grants from the Ministry of Education, Science, Sports, and Culture of Japan.

\section{References}

Ali RR, Reichel MB, Thrasher AJ, Levinsky RJ, Kinnon C, Kanuga N, Hunt DM, Bhattacharya SS (1996) Gene transfer into the mouse retina mediated by an adeno-associated viral vector. Hum Mol Genet 5: 591-594

Ali RR, Reichel MB, De Alwis M, Kanuga N, Kinnon C, Levinsky RJ, Hunt DM, Bhattacharya SS, Thrasher AJ (1998) Adeno-associated virus gene transfer to mouse retina. Hum Gene Ther 9: 81-86

Berns KI, Bohenzky RA (1987) Adeno-associated viruses: an update. Adv Virus Res 32: 243-306

Blom van Assendelft G, Hanscombe O, Grosveld F, Greaves DR (1989) The $\beta$-globin dominant control region activates homologous and heterologous promoters in a tissue-specific manner. Cell 56: 969-977

Bonifer C, Yannoutsos N, Kruger G, Grosveld F, Sippel AE (1994) Dissection of the locus control function located on the chicken lysozyme gene domain in transgenic mice. Nucleic Acids Res 22: 4202-4210

Cai H, Levine M (1995) Modulation of enhancer-promoter interactions by insulators in the Drosophila embryo. Nature 376: 533-536

Chung JH, Whiteley M, Felsenfeld G (1993) A 5' element of the chicken $\beta$-globin domain serves as an insulator in human erythroid cells and protects against position effect in Drosophila. Cell 74: 505-514

Chung JH, Bell AC, Felsenfeld G (1997) Characterization of the chicken $\beta$-globin insulator. Proc Natl Acad Sci USA 94: 575-580

Collis P, Antoniou M, Grosveld F (1990) Definition of the minimal requirements within the human $\beta$-globin gene and the dominant control region for high level expression. EMBO J 9: 233-240

Cone RD, Weber-Benarous A, Baorto D, Mulligan RC (1987) Regulated expression of a complete human $\beta$-globin gene encoded by a transmissible retrovirus vector. Mol Cell Biol 7: 887-897

Corces VG (1995) Chromatin insulators. Keeping enhancers under control. Nature 376: 462-463

Dzierzak EA, Papayannopoulou T, Mulligan RC (1988) Lineage-specific expression of a human $\beta$-globin gene in murine bone marrow transplant recipients reconstituted with retrovirus-transduced stem cells. Nature 331: 35-41

Einerhand MP, Antoniou M, Zolotukhin S, Muzyczka N, Berns KI, Grosveld F, Valerio D (1995) Regulated high-level human $\beta$-globin gene expression in erythroid cells following recombinant adenoassociated virus-mediated gene transfer. Gene Ther 2: 336-343

Ferster A, De Valck C, Azzi N, Fondu P, Toppet M, Sariban E (1992) Bone marrow transplantation for severe sickle cell anaemia. Br J Haematol 80: 102-105

Fisher KJ, Jooss K, Alston J, Yang Y, Haecker SE, High K, Pathak R, Raper SE, Wilson JM (1997) Recombinant adeno-associated virus for muscle directed gene therapy. Nature Med 3: 306-312

Geyer PK, Corces VG (1992) DNA position-specific repression of transcription by a Drosophila zinc finger protein. Genes Dev 6: 1865-1873

Goodman S, Xiao X, Donahue RE, Moulton A, Miller J, Walsh C, Young NS, Samulski RJ, Nienhuis AW (1994) Recombinant adenoassociated virus-mediated gene transfer into hematopoietic progeni- 
tor cells. Blood 84: 1492-1500

Grosveld F, van Assendelft GB, Greaves DR, Kollias G (1987) Position-independent, high-level expression of the human $\beta$-globin gene in transgenic mice. Cell 51: 975-985

Guy LG, Kothary R, DeRepentigny Y, Delvoye N, Ellis J, Wall L (1996) The $\beta$-globin locus control region enhances transcription of but does not confer position-independent expression onto the lacZ gene in transgenic mice. EMBO J 15: 3713-3721

Guy LG, Kothary R, Wall L (1997) Position effects in mice carrying a lac $\mathrm{Z}$ transgene in cis with the $\beta$-globin LCR can be explained by a graded model. Nucleic Acids Res 25: 4400-4407

Handa H, Shiroki K, Shimojo H (1977) Establishment and characterization of KB cell lines latently infected with adeno-associated virus type 1. Virology 82: 84-92

Holdridge C, Dorsett D (1991) Repression of hsp70 heat shock gene transcription by the suppressor of hairy-wing protein of Drosophila melanogaster. Mol Cell Biol 11: 1894-1900

Kalos M, Fournier RE (1995) Position-independent transgene expression mediated by boundary elements from the apolipoprotein B chromatin domain. Mol Cell Biol 15: 198-207

Kearns WG, Afione SA, Fulmer SB, Pang MC, Erikson D, Egan M, Landrum MJ, Flotte TR, Cutting GR (1996) Recombinant adenoassociated virus (AAV-CFTR) vectors do not integrate in a sitespecific fashion in an immortalized epithelial cell line. Gene Ther 3: 748-755

Kellum R, Schedl P (1991) A position-effect assay for boundaries of higher order chromosomal domains. Cell 64: 941-950

Kellum R, Schedl P (1992) A group of scs elements function as domain boundaries in an enhancer- blocking assay. Mol Cell Biol 12: 2424-2431

Kotin RM, Linden RM, Berns KI (1992) Characterization of a preferred site on human chromosome $19 \mathrm{q}$ for integration of adenoassociated virus DNA by non-homologous recombination. EMBO J 11: $5071-5078$

Leboulch P, Huang GM, Humphries RK, Oh YH, Eaves CJ, Tuan DY, London IM (1994) Mutagenesis of retroviral vectors transducing human $\beta$-globin gene and $\beta$-globin locus control region derivatives results in stable transmission of an active transcriptional structure. EMBO J 13: 3065-3076

Ley TJ, DeSimone J, Anagnou NP, Keller GH, Humphries RK, Turner PH, Young NS, Keller P, Nienhuis AW (1982) 5-Azacytidine selectively increases $\gamma$-globin synthesis in a patient with $\beta^{+}$thalassemia. $\mathrm{N}$ Engl J Med 307: 1469-1475

Lichter P, Cremer T, Borden J, Manuelidis L, Ward DC (1988) Delineation of individual human chromosomes in metaphase and interphase cells by in situ suppression hybridization using recombinant DNA libraries. Hum Genet 80: 224-234

Li Q, Stamatoyannopoulos G (1994) Hypersensitive site 5 of the human $\beta$ locus control region functions as a chromatin insulator. Blood 84: $1399-1401$

Lucarelli G, Galimberti M, Polchi P, Angelucci E, Baronciani D, Giardini C, Politi P, Durazzi SM, Muretto P, Albertini F (1990) Bone marrow transplantation in patients with thalassemia. N Engl J Med 322: 417-421

Malik P, McQuiston SA, Yu XJ, Pepper KA, Krall WJ, Podsakoff GM, Kurtzman GJ, Kohn DB (1997) Recombinant adeno-associated virus mediates a high level of gene transfer but less efficient integration in the K562 human hematopoietic cell line. J Virol 71: 1776-1783

McCown TJ, Xiao X, Li J, Breese GR, Samulski RJ (1996) Differential and persistent expression patterns of CNS gene transfer by an adeno-associated virus (AAV) vector. Brain Res 713: 99-107

Miller JL, Walsh CE, Ney PA, Samulski RJ, Nienhuis AW (1993) Single-copy transduction and expression of human $\gamma$-globin in K562 erythroleukemia cells using recombinant adeno-associated virus vectors: The effect of mutations in NF-E2 and GATA-1 binding motifs within the hypersensitivity site 2 enhancer. Blood 82: 1900-1906

Ney PA, Sorrentino BP, McDonagh KT, Nienhuis AW (1990) Tandem AP-1-binding sites within the human $\beta$-globin dominant control region function as an inducible enhancer in erythroid cells. Genes Dev 4: $993-1006$
Novak U, Harris EA, Forrester W, Groudine M, Gelinas R (1990) High-level $\beta$-globin expression after retroviral transfer of locus activation region-containing human $\beta$-globin gene derivatives into murine erythroleukemia cells. Proc Natl Acad Sci USA 87: 3386-3390

Philipsen S, Talbot D, Fraser P, Grosveld F (1990) The $\beta$-globin dominant control region: Hypersensitive site 2. EMBO J 9: 2159-2167

Ponnazhagan S, Yoder MC, Srivastava A (1997) Adeno-associated virus type 2-mediated transduction of murine hematopoietic cells with long-term repopulating ability and sustained expression of a human globin gene in vivo. J Virol 74: 3098-3104

Pruzina S, Hanscombe O, Whyatt D, Grosveld F, Philipsen S (1991) Hypersensitive site 4 of the human $\beta$-globin locus control region. Nucleic Acids Res 19: 1413-1419

Reitman M, Felsenfeld G (1990) Developmental regulation of topoisomerase II sites and DNase I- hypersensitive sites in the chicken $\beta$-globin locus. Mol Cell Biol 10: 2774-2786

Rolling F, Samulski RJ (1995) AAV as a viral vector for human gene therapy. Generation of recombinant virus. Mol Biotechnol 3: 9-15

Roseman RR, Pirrotta V, Geyer PK (1993) The su(Hw) protein insulates expression of the Drosophila melanogaster white gene from chromosomal position-effects. EMBO J 12: 435-442

Russell DW, Hirata RK (1998) Human gene targeting by viral vectors. Nat Genet 18: 325-330

Ryan TM, Behringer RR, Martin NC, Townes TM, Palmiter RD, Brinster RL (1989) A single erythroid-specific DNase I super-hypersensitive site activates high levels of human $\beta$-globin gene expression in transgenic mice. Genes Dev 3: 314-323

Sadelain M, Wang CH, Antoniou M, Grosveld F, Mulligan RC (1995) Generation of a high-titer retroviral vector capable of expressing high levels of the human $\beta$-globin gene. Proc Natl Acad Sci USA 92: 6728-6732

Sambrook J, Fritsch EF, Maniatis T (1989) Molecular cloning - a laboratory manual, 2nd edn. Cold Spring Harbor Laboratory Press, New York

Samulski RJ, Zhu X, Xiao X, Brook JD, Housman DE, Epstein N, Hunter LA (1991) Targeted integration of adeno-associated virus (AAV) into human chromosome 19. EMBO J 10: 3941-3950

Scott KS, Geyer PK (1995) Effects of the su(Hw) insulator protein on the expression of the divergently transcribed Drosophila yolk protein genes. EMBO J 14: 6258-6267

Snyder RO, Miao CH, Patijn GA, Spratt SK, Danos O, Nagy D, Gown AM, Winther B, Meuse L, Cohen LK, Thompson AR, Kay MA (1997a) Persistent and therapeutic concentrations of human factor IX in mice after hepatic gene transfer of recombinant AAV vectors. Nat Genet 16: 270-276

Snyder RO, Spratt SK, Lagarde C, Bohl D, Kaspar B, Sloan B, Cohen LK, Danos O (1997b) Efficient and stable adeno-associated virusmediated transduction in the skeletal muscle of adult immunocompetent mice. Hum Gene Ther 8: 1891-1900

Talbot D, Collis P, Antoniou M, Vidal M, Grosveld F, Greaves DR (1989) A dominant control region from the human $\beta$-globin locus conferring integration site-independent gene expression. Nature 338: 352-355

Talbot D, Philipsen S, Fraser P, Grosveld F (1990) Detailed analysis of the site 3 region of the human $\beta$-globin dominant control region. EMBO J 9: 2169-2177

Walsh CE, Liu JM, Xiao X, Young NS, Nienhuis AW, Samulski RJ (1992) Regulated high level expression of a human $\gamma$-globin gene introduced into erythroid cells by an adeno-associated virus vector. Proc Natl Acad Sci USA 89: 7257-7261

Weatherall DJ, Clegg JB (1981) The thalassemia syndromes, Blackwell, Oxford, UK

Wolfe L, Olivieri N, Sallan D, Colan S, Rose V, Propper R, Freedman MH, Nathan DG (1985) Prevention of cardiac disease by subcutaneous deferoxamine in patients with thalassemia major. N Engl J Med 312: $1600-1603$

Verma IM, Somia N (1997) Gene therapy - promises, problems and prospects. Nature 389: 239-242 